\title{
Uma proposta de inclusão da Astronomia na formação profissional superior em Ciências da Terra
}

\author{
Flávia Requeijo \\ Bolsista (2012-2014) do Museu de Astronomia e \\ Ciências Afins (MAST), Rio de Janeiro, RJ. \\ flavia.requeijo@gmail.com \\ Celso Dal Ré Carneiro \\ Instituto de Geociências, Universidade Estadual de \\ Campinas, Campinas, SP. \\ cedrec@ige.unicamp.br
}

\begin{abstract}
A PROPOSAL For InCLUSION OF ASTRONOMY IN Higher EDUCATION IN THE EARTH SCIENCES. The objective of this research is to study possible approaches on astronomy for students of undergraduate courses in Geology and Geography. We have analyzed contents at the undergraduate level of the Geography and Geology programs at the Institute of Geosciences of Unicamp, as well as their main bibliographical references. Based on Science Education studies, we have developed and evaluated an Astronomy course, offered to the Unicamp students. As a result of the application we have reformulated the proposal of Astronomy contents making it easier to be inserted in these undergraduate programs. The experience is adaptable to several teacher training courses. Introductory Astronomy courses for undergraduate students in Earth Sciences can contribute to deepen a temporal perspective, to form a critical look at current scientific models and to develop the understanding of the rhythms of life and, eventually, about the history of the Earth and the universe. Citation: Requeijo F., Carneiro C.D.R. 2014. Uma proposta de inclusão da Astronomia na formação do profissional de Ciências da Terra. Terræ Didatica, 10(3):305-318. http://www.ige.unicamp.br/terraedidatica/.
\end{abstract}

KEYWORDS: Astronomy, undergraduate programs, Earth Sciences, Geology, Geography, Geosciences, teacher training.

RESUMO O objetivo desta pesquisa é estudar possibilidades de abordagem da Astronomia e suas relações com as Ciências da Terra na formação de estudantes dos cursos de graduação em Geologia, Geografia e Licenciatura em Geografia. Para tanto, analisamos as ementas das disciplinas dos cursos do Instituto de Geociências da Unicamp (IG/Unicamp) e alguns dos livros didáticos de tais disciplinas. Com base nos estudos em Educação em Ciências, desenvolvemos e avaliamos uma disciplina de Astronomia, oferecida a estudantes dos cursos do IG/Unicamp. A análise dos resultados levou à reformulação da proposta, que reorganiza conteúdos de Astronomia que podem ser inseridos em cursos de graduação de Ciências da Terra, mas são adaptáveis a disciplinas equivalentes de formação docente. Conclui-se que disciplinas de Astronomia introdutória para estudantes de graduação nas carreiras de Ciências da Terra contribuem para aprofundar uma perspectiva temporal, formar um olhar crítico sobre modelos científicos vigentes e para desenvolver uma compreensão sobre os ritmos da vida e até mesmo sobre a história da Terra e do universo.

PALAVRAS-CHAVE: Astronomia, cursos de graduação, Ciências da Terra, Geologia, Geografia, Geociências, Licenciatura em Geografia. 


\section{Introdução}

A Astronomia é a ciência que estuda toda a matéria e radiação existentes além da Terra. As pesquisas em Astronomia envolvem a análise física, química, evolutiva e dinâmica dos corpos celestes, bem como a formação e a evolução do universo. Elas são impulsionadas pelas inovações tecnológicas que levaram a novos detectores para radiações ainda inexploradas até a metade do século XX, aos gigantescos telescópios em regiões altas e secas do planeta, e ainda aos telescópios espaciais, livres da interferência da atmosfera terrestre (Abdalla e Villela Neto 2005). O campo de pesquisa em Astronomia pode ser dividido em diferentes ramos ${ }^{1}$, de diversas formas. A divisão pode ser feita de acordo com os objetos ou métodos de pesquisa (Karttunen et al. 1996)

A Terra é de interesse da Astronomia por diversas razões. As observações realizadas do solo estão sujeitas aos efeitos atmosféricos, e os fenômenos da alta atmosfera e magnetosfera refletem o estado do espaço interplanetário. A Terra também é objeto de comparação para as Ciências Planetárias. Aliada à Geologia, a Astronomia proporciona um olhar para além do planeta Terra, permitindo compará-la aos demais planetas rochosos e satélites do Sistema Solar e assim extrapolar, com as devidas aproximações, os conceitos da Geologia para esses corpos celestes. Entretanto, como advertem Castilla e Pablo (2003), deve-se ter em mente que, aplicados a outros locais do Universo, os processos que acontecem ou que aconteceram na Terra nem sempre serão entendidos como os mesmos.

A Geologia é a ciência que: (a) reune um "corpo de conhecimentos sobre a Terra" e, ao mesmo tempo, (b) é "uma forma de se pensar sobre a Terra" (Baker 1999). Tal perspectiva pode ser igualmente extrapolada para a Astronomia. O princípio metodológico que permite à Geologia estudar o passado da Terra, o Atualismo (Carneiro et al. 1994), pode ser considerado, provavelmente, um princípio para o estudo de outros astros do universo, na medida em que estabelece a concepção de que as leis científicas são imutáveis e os processos geológicos, uniformes. Convém recordar que o Atualismo é uma

\footnotetext{
1 Considerando os objetos de pesquisa, a Astronomia pode ser dividida em: Astronomia de Posição; Mecânica Celeste; Astrofísica do Sistema Solar; Astrofísica Estelar; Astrofísica Galáctica e Extragaláctica; Astrofísica do Meio Interestelar e Cosmologia. Considerando os métodos de pesquisa, a Astronomia pode ser dividida de acordo com 0 comprimento de onda da radiação estudada. Sendo assim, pode-se falar da radioastronomia, da astronomia do infravermelho, do óptico, do ultravioleta, dos raios- $\mathrm{X}$ e raios gama (Karttunen et al. 1996:7)
}

das quatro vertentes surgidas do Uniformitarismo, que se apoia no estudo científico das causas, processos e efeitos dos fenômenos naturais (Carneiro et al. 1994:280). Quatro linhas de proposições foram reunidas para explicar as transformações na crosta terrestre como resultado de processos lentos e graduais que se repetem até hoje: (a) uniformidade das leis, (b) uniformidade dos processos terrestres [atualismo], (c) uniformidade de velocidades [gradualismo] e (d) uniformidade de condições [não-direcionalismo]. As duas primeiras concepções foram reunidas por Gould (1967) na concepção de Uniformitarismo Metodológico, ou Atualismo (Gould 1967), enquanto as outras duas compõem o Uniformitarismo Substantivo, que defende a uniformidade das velocidades dos processos (Baker 1999) desde o passado da Terra até os dias atuais e deixou de ser aceito como modelo explanatório do comportamento da natureza (Gould 1967).

O conhecimento construído por meio do estudo da Terra pode ajudar-nos a interpretar outros mundos; da mesma forma, o que viermos a descobrir muito além da Terra poderá ajudar-nos a reinterpretá-la, talvez provocando questionamentos sobre os modelos geológicos vigentes. A busca por explicações das novas realidades reveladas pelas recentes missões espaciais contribui para motivar os estudantes a olhar mais criticamente para os modelos científicos estabelecidos para o nosso planeta (López-Llamas 2003). A Astronomia compartilha com a Geologia uma perspectiva ampliada do tempo, na medida em que ambas operam com escalas de tempo da ordem de milhões a bilhões de anos. Cervato e Frodeman (2012) assinalam que a "consciência de Tempo Geológico é ferramenta muito poderosa", que ajuda a reorientar nosso sentido de tempo, e a fomentar "uma nova concepção de nossa consciência de realidade".

A Astronomia deve estar presente não só na formação dos geólogos como também na formação de geógrafos, por meio do estudo da interface entre os conhecimentos terrestres e os celestes, campo definido por Sobreira (2005) como Cosmografia Geográfica. A Cosmografia Geográfica "analisa as relações humanas e naturais com o espaço sideral e suas consequências para a sociedade e a natureza e, portanto, para a organização do espaço" (Sobreira 2005:115)

Para os licenciandos em Geografia é essencial saber conceitos básicos sobre Astronomia, uma vez que esta ciência é abordada na disciplina Geografia do Ensino Fundamental. Os Parâmetros Curricu- 
lares Nacionais (PCNs) propõem o estudo dos seguintes temas de Astronomia em Geografia nas $5^{\mathrm{a}}$ e $6^{\mathrm{a}}$ séries do Ensino Fundamental (atuais $6^{\circ} \mathrm{e}$ $7^{\circ}$ ano respectivamente) em:

Eixo Temático O estudo da natureza e sua importância para o homem

Tema: Os fenômenos naturais, sua regularidade e possibilidade de previsão pelo homem

Itens:

- Planeta Terra: a nave em que viajamos

- As águas e o clima

- Circulação atmosférica e estações do ano

No Eixo Temático $A$ cartografia como instrumento dos lugares e os lugares do mundo

Tema: Da alfabetização cartográfica à leitura crítica e mapeamento consciente

Itens:

- Os pontos cardeais, utilidades práticas e referenciais nos mapas.

- Orientação e medição cartográfica

- Coordenadas geográficas

Tema: Os mapas como possibilidade de compreensão e estudos comparativos das diferentes paisagens e lugares Itens:

- Os pontos cardeais e sua importância como sistema de referência nos estudos da paisagem, lugares e territórios

- A cartografia e os sistemas de orientação espacial.

A partir das orientações dos PCNs de Geografia do Ensino Fundamental, Sobreira (2002) considera que os temas de Astronomia que mais se aplicam à abordagem geográfica são:

- Orientação Geográfica;

- Estações do ano;

- Movimentos da Terra;

- Marés.

A pesquisa do tipo survey realizada por Bretones (1999) revelou existirem poucas universidades nas quais são oferecidas disciplinas obrigatórias ou optativas de astronomia para estudantes das áreas de Geociências (Geografia - Licenciatura e Bacharelado, e Geologia). Sobreira (2002) complementa explicando que, quando tais disciplinas são oferecidas, não atendem às necessidades dos estudantes de Geografia.

Assim sendo, o objetivo geral do presente trabalho foi pesquisar possibilidades de introduzir a Astronomia na formação de estudantes dos cursos de graduação em Geologia, Geografia e Licenciatura em Geografia por meio do estudo das suas relações com as Ciências da Terra.

\section{Objetivos e Desenvolvimento Metodológico da Pesquisa}

O objetivo geral do presente trabalho foi pesquisar possibilidades para a abordagem da Astronomia e suas relações com as Ciências da Terra na formação de estudantes dos cursos de graduação em Geologia, Geografia e Licenciatura em Geografia. Analisamos o Projeto Pedagógico de tais cursos (Basilici e Silva 2010) bem como as ementas de suas disciplinas para averiguar as possíveis relações entre Astronomia, Geologia e Geografia. Realizamos uma breve análise do conteúdo de Astronomia nos principais livros didáticos de Geologia introdutória, disciplina cuja ementa apresenta diversos tópicos de Astronomia. Adicionalmente, desenvolvemos uma disciplina de Astronomia voltada para os estudantes regularmente matriculados em cursos oferecidos pelo Instituto de Geociências da Unicamp. Sendo assim, a pesquisa envolveu o planejamento, implementação, aplicação prática e avaliação da proposta de disciplina para o referido público. Os objetivos específicos do trabalho dizem respeito a:

a) identificar a influência que uma visão introdutória da astronomia pode exercer na formação de graduandos que atuarão como geólogos e professores de Geografia no Ensino Fundamental;

b) propor a ementa de uma disciplina de introdução à astronomia voltada para estudantes de graduação das áreas das geociências.

c) planejar, executar e avaliar a referida disciplina.

Os dados da pesquisa realizada com os estudantes na implementação da proposta de disciplina de Astronomia são compostos por "anotações de campo", realizadas pela responsável pelo curso após as aulas, produções dos estudantes (exercícios, provas), pré-testes aplicados antes de determinadas atividades práticas e trabalho final da disciplina. As ementas das disciplinas oferecidas pelo Instituto de Geociências da Unicamp e os Parâmetros Curriculares Nacionais, foram analisadas com o objetivo de selecionar os temas de Astronomia que mais de adequariam à formação de geólogos, geógrafos e professores de Geografia.

Os pré-testes, exercícios e provas permitem-nos saber as ideias que os estudantes tinham sobre determinados conceitos de Astronomia e se estas 
mudaram ou não ao longo do curso. As anotações realizadas após as aulas ajudam a registrar o envolvimento dos estudantes em relação aos temas das aulas e atividades propostas, buscando investigar que aspectos das aulas ou atividades chamaram mais a atenção dos estudantes, motivaram-nos, instigaram-nos, ou mesmo os teriam surpreendido.

\section{O Problema}

Os dados e documentos foram analisados visando responder à seguinte questão, que se tornou a questão central de nossa investigação: Que conteúdos, objetivos educacionais e estratégias metodológicas devem compor uma disciplina de Astronomia Introdutória para estudantes de graduação das carreiras de Ciências da Terra?

Visando alcançar os objetivos supracitados, buscamos, dentre outros aspectos, identificar se os objetivos da disciplina de astronomia introdutória foram alcançados. Os objetivos da referida disciplina eram: (1) Motivar os estudantes a observar os fenômenos celestes2; (2) Estimular a análise crítica das representações dos fenômenos astronômicos nos livros didáticos de ciências e geografia do ensino fundamental; (3) Utilizar uma abordagem histórica dos conhecimentos astronômicos para promover a compreensão do processo de construção da ciência como algo que sofre interferência de fatores políticos, econômicos, sociais e culturais e que está em constante transformação; 4) Estimular nos estudantes um "olhar para além da Terra", que os permitissem vê-la como um corpo celeste.

\section{Astronomia na formação em Ciências da Terra da Unicamp}

Os cursos de Graduação do Instituto de Geociências (IG) da Unicamp foram criados em 1997 e receberam as primeiras turmas em 1998. Eles consistiam em: um curso diurno de Ciências da Terra com duração de três semestres, após os quais os estudantes escolhiam entre seguir o curso diurno de Geologia (bacharelado com duração total de 10 semestres) ou o curso diurno de Geografia (bacharelado com duração total de 8 semestres), e um curso noturno de Geografia (bacharelado e licenciatura com duração total de 10 semestres). A partir do ano de 2011 o Curso de Ciências da Terra foi eliminado e os estudantes passaram a ingressar diretamente nos cursos de Geologia ou Geografia mantendo-se, entretanto, um núcleo comum de disciplinas semestrais a serem cursadas em paralelo nos dois cursos. A duração mínima dos cursos, conforme sugestão da unidade, permanecera a mesma. O núcleo comum de disciplinas tem por objetivo introduzir os alunos aos conhecimentos básicos de Ciências da Terra e envolve conteúdos fundamentais de Geografia, Geologia, Biologia, Química, Estatística e Informática.

A relação entre natureza e sociedade é tema central desses cursos de graduação; abordada de forma multidisciplinar, integra Ciências Naturais e Humanas. Esta é considerada uma necessidade para que se possam formar profissionais em Geologia e Geografia que estejam "habilitados para dar sua contribuição para a solução dos grandes problemas emergentes do desenvolvimento econômico e social da humanidade, de forma a respeitar a estratégia de vida sustentável no planeta" (Basilici e Silva 2010:7).

$\mathrm{Na}$ ocasião do Ano Internacional do Planeta Terra [2007-2009], Nield e Derbyshire (2007) destacaram que os profissionais das áreas de Ciências da Terra exercem papel central no desenvolvimento das sociedades contemporâneas para a construção de um mundo sustentável. Seja na área de atuação técnica, ou de pesquisa ou de educação, todos podem contribuir. Devemos ser capazes de usar as riquezas da Terra sem desperdiçar recursos não-renováveis, e sem perturbar o equilíbrio dinâmico do Sistema Terra, que nos sustenta a todos. Para tal são necessárias pesquisas e o desenvolvimento de novas técnicas de exploração dos recursos terrestres. A população também precisa agir de forma consciente e responsável, e isso somente é possível com o conhecimento e valorização da Terra, com a percepção de que fazemos parte de um todo, e das diversas interações entre os sistemas terrestres oceanos, atmosfera, litosfera e biosfera (Carneiro et al. 2004). Quanto mais aprendemos sobre o nosso planeta, mais entendemos que devemos cultivá-lo, para o bem estar das futuras gerações (Carneiro 2008). As limitações introduzidas pela dimensão temporal dos processos naturais e antrópicos também precisa ser considerados: "nossas decisões atuais devem ser postas dentro de estrutura que inclua o passado e o futuro em termos de tempo geológico" (Cervato e Frodeman 2012). Sendo assim, o conhecimento em Ciências da Terra torna-se cada vez mais necessário para que os indivíduos e a sociedade possam se desenvolver e participar da vida contemporânea em todos os seus aspectos.

Para que os profissionais de Geologia e Geo- 
grafia estejam preparados a atuar na interface entre as pressões sobre os recursos naturais e o seu aproveitamento racional, estes devem receber uma "formação básica abrangente que os capacite a entender os processos que operam nas diferentes esferas do Sistema Terra, incluindo-se as interações, cada dia mais dominantes, da sociedade com a natureza" (Basilici e Silva 2010:9). Diretamente relacionado a esta demanda na formação de tais profissionais, destacamos um dos cinco eixos temáticos que a formação do bacharel em Geologia deve privilegiar, para que o mesmo alcance o perfil teórico-prático desejado:

O conhecimento integrador da visão de Ciência do Sistema Terra, que requer formação sólida em ciências básicas, orientada para o entendimento dos processos físicos, químicos e geológicos e climáticos que operam no Sistema Terra (passado, presente e futuro), além da base instrumental necessária. (Basilici e Silva 2010)

Segundo Clark e Carpenter (2006), o termo "Sistema Terra" começou a ser usado em 1986 após a publicação de um relatório da NASA sobre o programa Ciência do Sistema Terra: Um Programa para Mudança Global, que foi uma tentativa de estabelecer coleta e interpretação de dados de forma interdisciplinar, usando satélites para a observação de mudanças globais. A Ciência do Sistema Terra sugerida no relatório é uma proposta para a compreensão de como a Terra funciona. Considera a Terra como um sistema no qual seus componentes não podem ser compreendidos em separado (Barstow e Geary 2002). O Sistema Terra pode ser compreendido como subdividido em 3 geosistemas que interagem entre si (Press et al. 2006):

- Sistema do clima (atmosfera, hidrosfera, biosfera e litosfera)

- Sistema das placas tectônicas (litosfera, astenosfera e manto)

- Sistema do geodínamo (núcleo externo e interno)

A Terra também é considerada um sistema aberto, pois troca massa e energia com o restante do cosmos. A energia proveniente do Sol governa diversos processos do sistema clima, que também sofre influência da dinâmica interna do planeta.

Identificamos aqui uma interface entre Astronomia e Geologia. A primeira, que estuda toda a matéria e radiação existentes além da Terra, e a segunda, que necessita conhecer a radiação incidente no planeta para estudar os processos que operam nos subsistemas terrestres.

Deve-se notar que os seres humanos são parte integrante desse complexo sistema. Assim como a atividade humana alterou o meio natural (os solos, os cursos dos rios, a composição da atmosfera), somos igualmente afetados pelas mudanças no ambiente. Pitman (2005) ressalta a importante contribuição dos geógrafos, com ampla experiência em Geografia Física e Humana, para a reflexão sobre as interações entre as esferas social e natural do planeta. Carneiro e Gonçalves (2013) destacam a relevância da visão sistêmica de Ciência do Sistema Terra para a formação do geógrafo, pois ela permite um tratamento mais integrado das esferas social e natural, assim como a construção uma visão sistêmica e histórica do planeta.

No item a seguir investigamos como a Astronomia se faz presente nas disciplinas dos cursos de graduação do IG-Unicamp por meio da análise das ementas disciplinares e dos principais livros didáticos utilizados na formação desses profissionais.

\section{Disciplinas que abordam conceitos de Astronomia e alguns de seus livros didáticos}

Uma análise preliminar das ementas de disciplinas oferecidas pelo Instituto de Geociências da Unicamp revela que há diversos temas de Astronomia presentes na programação das mesmas. Destacamos na Tabela 1 as disciplinas e em quais cursos elas se inserem.

$\mathrm{Na}$ Tabela 2 listamos temas de Astronomia ou Cosmografia Geográfica que têm relação com o conteúdo de tais disciplinas.

Duas importantes disciplinas que abordam temas de Astronomia nos primeiros semestres do núcleo comum são Ciência do Sistema Terra I e II. Dependendo da escolha do curso, os estudantes podem cursar entre 7 e 9 disciplinas que contemplem algum tópico de Astronomia relacionado ao tema central da mesma.

Dentre os livros indicados nas bibliografias dos referidos cursos, analisamos primeiramente duas obras de geologia introdutória: Teixeira et al. (2008) e Press et al. (2006).

O livro Decifrando a Terra (Teixeira et al. 2008) foi desenvolvido por pesquisadores e professores do Instituto de Geociências (IGc-USP), do Instituto de Astronomia, Geofísica e Ciências Atmosféricas (IAG-USP), Instituto Oceanográfico (IO-USP) e outras universidades. São mais de 30 autores, sendo que cada capítulo foi redigido por pelo menos dois 
Tabela 1. Disciplinas do Instituto de Geociências que abordam temas de Astronomia. As disciplinas oferecidas em caráter obrigatório são marcadas com "O" e aquelas em caráter eletivo, marcadas com "E".

\begin{tabular}{c|c|c|c|c}
\hline \multirow{2}{*}{$\begin{array}{c}\text { Código da } \\
\text { Disciplina }\end{array}$} & Nome da Disciplina & Geologia & $\begin{array}{c}\text { Bacharelado } \\
\text { em Geografia }\end{array}$ & $\begin{array}{c}\text { Licenciatura } \\
\text { em } \\
\text { Geografia }\end{array}$ \\
\cline { 3 - 5 } & Ciência do Sistema Terra & O & O & O \\
\hline GN106 & Cartografia Sistemática & O & O & O \\
\hline GN107 & Introdução ao Sensoriamento Remoto & O & O & O \\
\hline GN108 & Ciência do Sistema Terra II & O & O & - \\
\hline GN208 & Geoquímica & O & - & - \\
\hline GE703 & Geofísica & O & - & - \\
\hline GE706 & Geologia Histórica do Brasil & O & - & - \\
\hline GE707 & Sensoriamento Remoto e Fotogeologia & O & - & O \\
\hline GF302 & Sensoriamento Remoto & - & $\mathbf{O}$ & $\mathbf{O}$ \\
\hline GF410 & Climatologia I & $\mathbf{E}$ & $\mathbf{O}$ & \\
\hline GF403 & Hidrologia e Oceanografia & - & $\mathbf{O}$ & \\
\hline
\end{tabular}

Códigos: Disciplina obrigatória (O) e Disciplina eletiva (E)

deles. O livro está organizado em quatro unidades, que procuram abordar os temas desde a escala global até a local.

A primeira unidade apresenta a origem do Universo e da Terra, os processos internos terrestres de grande escala, as principais características da atmosfera e as mudanças climáticas antigas e recentes. A segunda unidade destaca a composição da Terra sólida, os minerais e rochas, o solo e o ciclo da água. Na terceira são abordados diversos processos geológicos e a Escala de Tempo Geológico. A quarta e última unidade apresenta os recursos naturais e aborda a questão da sustentabilidade das atividades humanas no planeta, por meio de uma discussão que contempla o passado, o presente e o futuro da Terra. O primeiro capítulo, intitulado A Terra e suas origens, trata da origem e estrutura do universo, trazendo também elementos de evolução estelar e da formação de elementos químicos, para então abordar a origem do sistema solar. Ou seja, apresenta a história do universo antes mesmo da formação do Sol e da Terra. Tais eventos ocorridos há mais de 5 bilhões de anos são importantes para explicar a distribuição de elementos químicos observada no nosso planeta. Além disso, o capítulo apresenta a seção planetologia comparada, ricamente ilustrada, a qual descreve os planetas terrestres, os planetas jovianos, os planetas anões e os corpos menores do sistema solar (asteroides, cometas e objetos transnetunianos).

O livro Para entender a Terra (Press et al. 2006) tem a proposta de apresentar os componentes do sistema Terra e, a partir desse conceito abordar os processos da dinâmica interna e externa do planeta, buscando evidenciar as relações entre os sistemas terrestres, seus componentes e processos geológicos, com ênfase na teoria da tectônica de placas. Diferente de Teixeira et al. (2008), o livro não apresenta um capítulo que concentre conteúdos de Astronomia. Em seu primeiro capítulo, Estruturando um planeta, são abordadas a origem da Terra e dos demais corpos do sistema solar. São apresentadas também as principais características dos planetas terrestres (Mercúrio, Vênus, Terra e Marte).

\section{Astronomia, Geologia e Geografia: relações pertinentes para os estudantes de Ciências da Terra}

A análise da literatura, das ementas de disciplinas de geociências dos livros didáticos de geologia introdutória possibilitou a organização das relações entre Astronomia, Geologia e Geografia em eixos temáticos, que serão descritos nessa seção. A tabela 3 apresenta tais eixos temáticos, assim como os tópicos de Astronomia associados a cada um deles.

Apresentamos a seguir alguns conceitos relevantes e tecemos considerações preliminares sobre a necessidade de que tópicos relacionados à Astronomia sejam veiculados em cursos superiores de Ciências da Terra 
Tabela 2. Temas de Astronomia ou de Cosmografia Geográfica (Sobreira 2005) abordados nas disciplinas do Instituto de Geociências da Unicamp

\begin{tabular}{|c|c|c|c|}
\hline Código & $\begin{array}{l}\text { Nome da } \\
\text { Disciplina }\end{array}$ & Temas presentes na ementa & $\begin{array}{l}\text { Temas de Astronomia } \\
\text { relacionados }\end{array}$ \\
\hline GN106 & $\begin{array}{c}\text { Ciência do Sistema } \\
\text { Terra I }\end{array}$ & A Terra como um sistema & $\begin{array}{c}\text { Movimentos da Terra } \\
\text { Insolação/Estações do ano }\end{array}$ \\
\hline GN208 & $\begin{array}{c}\text { Ciência do Sistema } \\
\text { Terra II }\end{array}$ & $\begin{array}{l}\text { As escalas temporais e espaciais } \\
\text { dos processos naturais e sociais }\end{array}$ & $\begin{array}{l}\text { Escala de tempo astronômica } \\
\text { Idade do Universo }\end{array}$ \\
\hline GN207 & $\begin{array}{l}\text { Introdução ao } \\
\text { Sensoriamento } \\
\text { Remoto } \\
\end{array}$ & \multirow{3}{*}{$\begin{array}{l}\text { O espectro eletromagnético } \\
\text { Interação entre a radiação } \\
\text { eletromagnética e os materiais da } \\
\text { superfície da Terra } \\
\text { Interpretação de dados de } \\
\text { satélites artificiais }\end{array}$} & \multirow{3}{*}{$\begin{array}{c}\text { Radiação astrofísica/ Radiação } \\
\text { Solar } \\
\text { Leis de Kirchoff } \\
\text { Mecânica celeste/elementos } \\
\text { orbitais }\end{array}$} \\
\hline GE707 & $\begin{array}{l}\text { Sensoriamento } \\
\text { Remoto e } \\
\text { Fotogeologia }\end{array}$ & & \\
\hline GF302 & $\begin{array}{l}\text { Sensoriamento } \\
\text { Remoto }\end{array}$ & & \\
\hline GN108 & $\begin{array}{l}\text { Cartografia } \\
\text { Sistemática } \\
\end{array}$ & $\begin{array}{l}\text { Uso de cartas e mapas em } \\
\text { ciências da terra }\end{array}$ & $\begin{array}{l}\text { Orientação geográfica } \\
\text { Movimento da Terra }\end{array}$ \\
\hline GE503 & Geoquímica & $\begin{array}{l}\text { Abundância dos elementos } \\
\text { químicos no Universo e no } \\
\text { Sistema Solar }\end{array}$ & $\begin{array}{l}\text { Origem dos elementos químicos } \\
\text { (nucleossíntese) }\end{array}$ \\
\hline GE703 & Geofísica & $\begin{array}{l}\text { Campo magnético terrestre } \\
\text { Elementos radioativos naturais }\end{array}$ & $\begin{array}{l}\text { Interações entre magnetosfera, } \\
\text { ventos solares e meio } \\
\text { interplanetário; } \\
\text { Origem da Terra e do Sistema } \\
\text { Solar; datação de meteoritos }\end{array}$ \\
\hline GE706 & $\begin{array}{c}\text { Geologia Histórica } \\
\text { do Brasil }\end{array}$ & $\begin{array}{c}\text { Origem do Sistema Solar e da } \\
\text { Terra } \\
\text { Origem dos elementos } \\
\text { Radioatividade, calor e } \\
\text { geocronologia }\end{array}$ & $\begin{array}{l}\text { Formação estelar e planetária } \\
\qquad \text { Nucleossíntese }\end{array}$ \\
\hline GF410 & Climatologia I & $\begin{array}{c}\text { Distribuição e balanço global de } \\
\text { radiação }\end{array}$ & $\begin{array}{c}\text { Radiação solar } \\
\text { Movimentos da Terra }\end{array}$ \\
\hline GF403 & $\begin{array}{l}\text { Hidrologia e } \\
\text { Oceanografia }\end{array}$ & $\begin{array}{l}\text { Oceanos e mares, movimento das } \\
\text { águas oceânicas }\end{array}$ & $\begin{array}{c}\text { Gravitação e efeito de marés nos } \\
\text { oceanos } \\
\text { Fases da Lua }\end{array}$ \\
\hline
\end{tabular}

\section{Interações Sol-Terra-Lua}

O estudo do sistema Sol-Terra-Lua é de grande importância para os estudantes de Ciências da Terra. O Sol é a principal fonte de energia para os processos que atuam na superfície terrestre, especialmente aqueles do sistema clima. O estudo da radiação solar e sua interação com o campo magnético terrestre podem fornecer informações sobre a circulação de ar na atmosfera. $\mathrm{O}$ registro da atividade solar em longas escalas de tempo pode auxiliar a compreensão dos processos do sistema clima em uma visão global.
A interação gravitacional entre Sol, Terra e Lua é responsável pelo movimento da Terra no espaço. A Terra movimenta-se ao redor do Sol em uma órbita elíptica de baixa excentricidade, ou seja, quase circular. Simultaneamente o planeta rotaciona ao redor de um eixo, que se encontra inclinado de $66,5^{\circ}$ aproximadamente, em relação ao plano da órbita terrestre, conforme a Figura 1.

Em curtos intervalos de tempo, de algumas décadas ou séculos, podemos dizer que a direção do eixo de rotação terrestre não sofre variações e, devido a esse fato, em distintas épocas do ano a luz 
Tabela 3. Eixos temáticos e tópicos de intersecção entre Astronomia, Geologia e Cosmografia Geográfica que surgiram da análise das ementas oferecidas no IG/Unicamp.

\begin{tabular}{|c|c|}
\hline Eixo Temático & Tópicos \\
\hline Interação Sol-Terra-Lua & $\begin{array}{l}\text { - Interação gravitacional - dinâmica orbital, movimento da } \\
\text { Terra e movimento aparente do céu, marés } \\
\text { - Interação entre radiação solar, magnetosfera e esferas } \\
\text { terrestres }\end{array}$ \\
\hline Origens & $\begin{array}{l}\text { - A origem comum do Sol e dos planetas } \\
\text { - Os elementos químicos encontrados na Terra e no Sol } \\
\text { - Origem dos elementos químicos (nucleossíntese) }\end{array}$ \\
\hline Dimensão temporal & $\begin{array}{l}\text { - As enormes escalas de tempo envolvidas dos processos } \\
\text { naturais em relação aos processos sociais } \\
\text { - Eventos anteriores à formação do nosso planeta que foram } \\
\text { fundamentais para a caracterização da Terra }\end{array}$ \\
\hline
\end{tabular}

solar incide de forma diferente sobre as diversas regiões do planeta. Tal diferença de incidência de radiação solar causa o fenômeno conhecido como "estações do ano". Quando os raios solares incidem mais perpendicularmente à superfície terrestre, a radiação incidente espalha-se por uma área menor do que quando os raios solares incidem mais obliquamente em relação à superfície.

A inclinação do eixo de rotação terrestre em relação ao plano de sua órbita, conhecido como eclíptica, é responsável pela divisão da Terra nas chamadas zonas climáticas. Além disso, influencia a forma como nós observamos os movimentos celestes ao longo do ano, do ponto de vista da superfície terrestre.

No contexto do Sistema Sol-Terra-Lua, é frequente a afirmação, nos livros de geografia do ensino fundamental, de que o Sol surge todas as manhãs no horizonte no ponto cardeal Leste. Tal afirmação seria verdadeira se o eixo de rotação terrestre fosse inclinado de $90^{\circ}$ em relação à eclíptica, sem sofrer variações. Entretanto, o que observamos é uma variação da posição do nascente e do poente ao longo do ano. Mas, após aproximadamente 365 dias - um ano solar - o Sol volta a nascer no mesmo ponto e reinicia seu ciclo anual. A variação marca as estações do ano e constitui a base do nosso calendário.

Os pontos cardeais, segundo definição de Mourão (2008), são quatro pontos situados no horizonte de um observador, a $90^{\circ}$ um do outro, cujas direções servem à orientação topográfica. Os pontos cardeais Leste (E) e Oeste (W) são definidos pela interseção entre o horizonte e o equador celeste.

A Lua, nosso satélite natural, teve suas principais fases usadas como marcadores de tempo em diversos calendários. Tem influência no movimen- to periódico dos polos terrestres e exerce efeitos de maré aproximadamente duas vezes maiores que os solares (Silveira 2003). As marés por sua vez têm importância não somente na vida marinha, no transporte e deposição de sedimentos ao longo da costa, como nas atividades econômicas e políticas.

\section{Nossas Origens}

O segundo eixo temático evidente da análise está relacionado às origens do Sol, da Terra e até mesmo da nossa espécie. Somos formados dos mesmos elementos químicos presentes no Sol e nos demais astros. Tal descoberta se tornou possível por meio de uma técnica denominada espectroscopia, que analisa a luz dos corpos celestes dispersada por um prisma ou rede de difração e permite determinar a abundância dos elementos químicos no universo. O estudo da origem dos elementos químicos e de da "evolução química" do Universo permite que os estudantes de Ciências da Terra entrem em contato com uma escala de tempo maior ainda que a da história da Terra.

Os modelos cosmológicos indicam que as primeiras estrelas surgiram cerca de 100 milhões de anos após o início da expansão do universo, conhecido como Big Bang. Eram, provavelmente, muito densas e luminosas, formadas apenas por hidrogênio e hélio. Elas produziram e espalharam os elementos químicos pesados pelo espaço, permitindo a formação de sistemas planetários como o nosso Sistema Solar. Cerca de 9 bilhões de anos após o Big Bang, em um dos braços espirais da nossa galáxia, começava a se contrair uma nebulosa de gás e poeira que daria origem ao Sol e aos demais corpos do Sistema Solar. Uma vez que gerações anteriores de estrelas espalharam elementos químicos pesados 


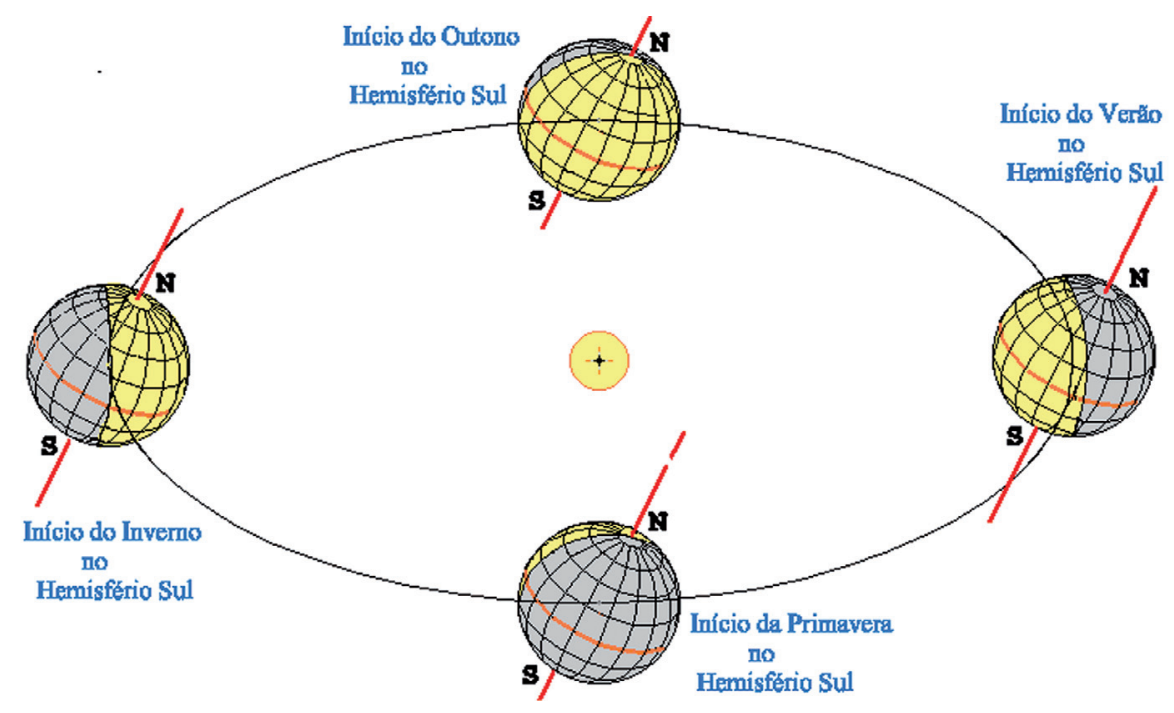

Figura 1. Representação da posição terrestre em relação ao Sol para justificar as estações do ano. Note que na imagem o plano da órbita terrestre está inclinado em relação ao observador Fonte: Centro de Divulgação da Astronomia/ USP. (http://www.cdcc.usp.br/cda/producao/sbpc93/)

pela Via Láctea, a nebulosa solar continha elementos como o carbono, o ferro, o oxigênio, o silício e o alumínio. Isso permitiu a formação dos planetas terrestres - Mercúrio, Vênus, Terra e Marte - de milhares de outros corpos rochosos que habitam nosso sistema e o surgimento de formas de vida baseada em carbono (Oliveira e Saraiva 2000)

\section{A dimensão temporal}

"O tempo geológico é uma das ideias culturalmente mais relevantes na história do pensamento" (Cervato e Frodeman 2012).

O tempo é um conceito de relevância científica, filosófica e histórica. Ao longo de séculos vem sendo alvo de estudo e reflexão de filósofos e cientistas, podendo ser entendido de diferentes formas, como a quarta dimensão do Universo, como sendo cíclico ou linear, absoluto ou relativo. Uma grande variedade de fenômenos naturais foi estudada para interpretar os ritmos da vida, a história da Terra e do Universo. Nessa diversidade há fenômenos facilmente perceptíveis, como o nascer e o ocaso do Sol, e que desde sempre puderam ser empregados como reguladores de tempo e os processos muito lentos e por isso imperceptíveis ao longo de uma vida humana, como as alterações sofridas pelas rochas terrestres ou pelas estrelas. Perceber as grandes escalas de tempo envolvidas na Astronomia e na Geologia é fundamental para que os estudantes possam situar os fenômenos astronômicos, terrestres e humanos no tempo. As implicações dessa percepção e desse entendimento são imensas e não têm sido percebidas pelas pessoas, pelas empresas e pelos governos nacionais.

A atual tendência de estímulo ao consumo desenfreado das pessoas e sociedades conflita claramente com os limites dados pelas lentas velocidades de reposição natural de recursos. A produção de alimentos, a extração de água para abastecimento humano ou até mesmo a produção de bens e serviços impulsionam retirada de bens cuja reposição é consideravelmente mais demorada que as taxas de extração. Cervato e Frodeman (2012) consideram "improvável que a sociedade queira calcular o custo da erosão dos solos ou a perda de um aquífero nos próximos 100 ou 1.000 anos"; entretanto, assinalam questões cujo enfrentamento e equacionamento são inadiáveis, como a "necessidade de se buscar modos de integrar o prazo longo imediato do tempo geológico dentro de nosso planejamento econômico, pelo menos em termos de limites ou regulamentos de nossos hábitos econômicos". A formação de cidadãos conscientes e sociedades sustentáveis envolve a análise e apropriação de conhecimentos derivados das escalas temporais que governam os processos geológicos e naturais.

\section{A Astronomia na formação dos alunos de Ciências da Terra: uma proposta}

A proposta inicial foi colocada em prática com os alunos do curso de Ciências da Terra da Unicamp na forma de uma disciplina eletiva, oferecida no segundo semestre de 2009 com a carga horária de 2 
horas semanais. Originalmente as atividades tinham sido idealizadas para os alunos de licenciatura em Geografia, ou seja, nossas ações pretendiam contemplar tanto temáticas de Astronomia quanto aquelas relacionadas ao ensino de Astronomia na disciplina Geografia dos ensinos fundamental e médio. Entretanto não excluímos a possibilidade de os alunos dos cursos de Geologia se inscreverem na disciplina.

A disciplina foi aberta com o título de "Tópicos Especiais em Geografia”, nome padrão para disciplinas eletivas, e subtítulo "Elementos de Astronomia para o Ensino de Geografia", escolhido pelos autores. Houve número considerável de inscritos, 28 , e poucas desistências, duas, o que demonstra o grande interesse dos alunos de Ciências da Terra pelo tema. O curso contou com onze aulas e uma visita a um observatório - Observatório Municipal de Campinas, além dos encontros para avaliação e apresentação de seminários. O curso buscou adotar estratégias metodológicas apoiadas em teorias construtivistas de aprendizagem, que consideram o conhecimento como algo construído a partir de interações com o ambiente social, especialmente no modelo da mudança conceitual, fundamentado nos trabalhos de Posner (1982) e Hewson e Thorley (1989).

\section{Perfil dos participantes do curso}

Os inscritos na disciplina eram, em sua maioria, alunos do primeiro ano do curso de Ciências da Terra (Fig. 2). Dos 28 inscritos, 15 (54\%) eram alunos do primeiro ano. Desses, a maioria afirmou que optaria por Geologia no segundo ano de graduação. Dois estudantes apenas cursavam a licenciatura em Geografia. Nenhum deles havia cursado a disciplina Estágio Supervisionado ou preparado uma aula ou apresentação sobre temas de Astronomia. O grupo contava ainda com sete alunos de Geologia, dois do bacharelado em Geografia, uma mestranda do programa de pós-graduação em Ensino e História de Ciências da Terra, uma professora de geografia dos níveis de ensino fundamental e médio e um aluno do curso de Bacharelado em Física Médica. Dois alunos cursaram a disciplina como ouvintes: uma aluna do curso de Bacharelado em Geografia e outra da Engenharia Agrícola da Unicamp. Apenas dois alunos trancaram a disciplina.

\section{Ementa da Disciplina Elementos de Astronomia para o Ensino de Geografia}

Durante o planejamento da disciplina curso e escolha do programa foi necessário levar em consi- deração diversos fatores: a natureza introdutória do curso; o tempo disponível para aulas e tarefas extracurriculares; o perfil dos estudantes e os resultados das pesquisas na área de Educação em Ciências, em especial Educação em Astronomia. O tempo disponível - duas horas semanais em 17 encontros - não nos permitiria um programa muito abrangente ou grandes aprofundamentos em determinadas questões. A ementa e o programa inicial proposto para a disciplina foram os seguintes:

Ementa: Fundamentos de Astronomia: noções de escala e sistemas de medidas astronômicas, movimento aparente dos astros, fenômenos celestes, Sistema Solar, noções de evolução estelar, a Astronomia no ensino fundamental e problemas relacionados à representação de conceitos astronômicos nos livros didáticos de Geografia e Ciências.

O Programa do Curso acha-se na Tabela 4.

\section{Principais Resultados}

Os pré-testes aplicados aos estudantes revelam que o conhecimento apresentado antes das principais atividades práticas estava, em muitos casos, compatível com algumas das concepções espontâneas mais frequentes em Astronomia (Langhi 2011). Podemos citar como exemplo o conceito de orientação geográfica, sobre o qual os estudantes não conheciam como os pontos cardeais são definidos e acreditavam que o Sol nascia no ponto cardeal Leste e se punha do ponto cardeal Oeste. A maioria também desconhecia o motivo para as fases da Lua. Apesar de o tema ter sido discutido na disciplina Ciência do Sistema Terra I, ainda encontramos alguns estudantes que acreditavam ser a variação da distância Sol-Terra a causa das estações do ano. $O$ resultado indica a necessidade de realizar mais discussões sobre o assunto, de preferência fazendo uso de modelos tridimensionais.

Um questionário foi aplicado na primeira aula para conhecermos a experiência prévia dos alunos com a Astronomia, o interesse sobre temas astronômicos e suas expectativas em relação ao curso. As respostas às questões abertas foram organizadas na forma de Discursos do Sujeito Coletivo (DSC). O Discurso do Sujeito Coletivo consiste em uma proposta de coleta, organização, tabulação e análise de dados qualitativos de natureza verbal (Lefevvre 2005). Trata-se de ferramenta metodológica que busca apreender o pensamento de uma coletividade compondo discursos-síntese a partir dos depoimentos ou textos produzidos pelos indivíduos pesquisados. 
Tabela 4. Programa inicialmente proposto para o curso. Permearam o programa questões relacionadas ao ensino de astronomia, problemas encontrados nos livros didáticos, construção de materiais didáticos e elaboração de atividades práticas, de modo que não foi prevista uma unidade específica sobre esses assuntos

1. Introdução à Astronomia de Posição

i. Abóbada celeste, horizonte, zênite

ii. Equador celeste, pólos celestes, pontos cardeais

iii. Esfera celeste reta, oblíqua e paralela

iv. Sistemas de coordenadas horizontais e equatoriais

2. Observação do Céu

i. Movimentos Celestes Aparentes

ii. Movimento aparente das estrelas

iii. Movimento aparente dos planetas

- Os Modelos Geocêntrico e Heliocêntrico

- Configurações Planetárias

- Leis de Kepler

- Lei da Gravitação Universal

iv. Movimento aparente do Sol

- A Eclíptica

- Zodíaco

- As estações do Ano

3. O Sistema Sol-Terra-Lua

i. Forma e movimento da Terra

ii. Fases da Lua, Eclipses e Marés

4. Sistemas de Medida de Tempo

i. Tempo Solar

ii. Tempo Sideral

iii. Fusos Horários

iv. Gnômom e relógio de Sol

v. Calendários

5. Nossa Localização no Universo

i. Noções de escala do Sistema Solar e Universo

ii. O Sistema Solar

- O Sol

- Planetas terrestres

- Planetas gasosos

- Planetas anões e pequenos corpos do Sistema Solar

6. Instrumentos e Observatórios Astronômicos

7. Noções de Astrofísica

i. O espectro eletromagnético

ii. Espectroscopia

iii. O efeito doppler

iv. O surgimento da Astrofísica

v. As estrelas e suas vidas

vi. A Via Láctea

- A vizinhança solar

- Nebulosas e aglomerados estelares

- Nuvens de Magalhães, galáxias satélite e o grupo local 
Com relação à motivação para inscreverem-se no curso, foi possível identificar nas respostas forte presença das expressões "curiosidade", "interesse" e "encantamento" causados pela Astronomia desde a infância, mas também foi detectada a preocupação com a formação profissional em suas respostas, como podemos perceber nos discursos-síntese a seguir, confeccionados com extratos de diferentes depoimentos individuais, em resposta à questão: Qual foi (ou quais foram) a principal motivação em cursar esta disciplina?

DSC 1.5 - Principalmente por achar importante para a minha formação. Sempre gostei muito de Astronomia e fiquei um tanto quanto decepcionado quando percebi que no curso de geologia não a teria como disciplina.

DSC 1.6 - Como o curso de geologia não oferece nenhuma disciplina de astronomia, eu vi nessa disciplina uma excelente oportunidade, além de ser a possibilidade de estudar isso em uma instituição como a Unicamp.

Quando perguntados sobre suas expectativas em relação ao curso, evidenciou-se a preocupação com a formação profissional, seja da parte dos estudantes de licenciatura em Geografia ou dos estudantes de Geologia. Ambos os grupos parecem achar, por motivos diferentes, que a Astronomia pode contribuir para sua formação. Entretanto esta era uma preocupação de uma parcela pequena da turma. A maioria dos estudantes parece não perceber as possíveis contribuições dos conhecimentos astronômicos para sua formação, tendo optado pelo curso para satisfazer seus interesses pessoais. $O$ interesse a curiosidade são aspectos positivos que puderam ser usados para engajá-los na disciplina. Para tanto era necessário conciliar expectativas e interesses destes diferentes grupos para produzir ações educativas geradoras de reflexão, motivação e encanto.

O trabalho final da disciplina proporcionou a oportunidade de os estudantes analisarem livros didáticos de geografia e ciências. $\mathrm{Na}$ investigação os estudantes procuraram descrever como os conteúdos estavam organizados e analisar sua estrutura e organização. Puderam também ponderar sobre a apresentação dos conteúdos, seja por meio de textos ou imagens, avaliando até que ponto os conceitos estariam adequados para leitores com idades entre 10 e 12 anos, ou se as imagens ou textos poderiam conduzi-los a concepções errôneas. Buscaram ainda nas obras referências à história da ciência/ astronomia e à profissão do cientista ou astrônomo, analisando como estes eram caracterizados.

As respostas ao questionário aplicado após o término do curso indicam que a disciplina foi capaz de motivar os estudantes a observar mais o céu, em especial, as fases da Lua e as diferentes posições de nascer e ocaso. A maioria dos estudantes considera que a Astronomia deve estar presente na formação de geólogos e geógrafos.

\section{Discussão}

Desde a segunda metade da década de 1970, diversas pesquisas têm mapeado as chamadas concepções espontâneas em astronomia (Langhi, 2011) e apontado para temas de grande dificuldade para crianças e jovens. Há também indícios de que a formação básica, termo que, no Brasil reúne os níveis de ensino fundamental e médio, e até mesmo a formação superior, não têm sido capazes de promover mudanças em tais concepções.

Segundo o modelo de mudança conceitual de Hewson e Thorley (1989), a mudança conceitual é um processo no qual a concepção alternativa do estudante perde status e a concepção científica construída em aula ganha status. Para que a mudança conceitual ocorra é necessário que algumas condições sejam satisfeitas. As condições se referem às concepções dos alunos, que devem se perguntar quanto à inteligibilidade, plausibilidade e proveito de suas concepções: eles entendem o que elas significam? Elas fazem algum sentido e podem ser conciliadas com suas outras concepções? Elas podem ser usadas para resolver problemas? A quarta condição a ser atendida está diretamente relacionada à mudança de status da concepção do estudante e se refere à satisfação do mesmo quanto aos seus conceitos. Uma pessoa torna-se insatisfeita com uma concepção quando ela se torna ininteligível, implausível ou não proveitosa. Sendo assim, tal concepção tenderá a perder status.

Quando uma pessoa considera uma nova concepção, podem acontecer várias situações, dentre as quais a incorporação da nova concepção ao conjunto de concepções pré-existentes (captura conceitual) e a substituição de uma nova concepção por outra conflitante. Ambos os processos são denominados mudança conceitual.

$\mathrm{Na}$ disciplina oferecida buscamos utilizar as concepções alternativas mais comuns em astronomia (Bisch 1998, Langhi 2011), e que muitas vezes coincidiam com as dos nossos estudantes, como pontos de partida para a construção de ideias cientificamente corretas. Procuramos criar situações nas quais as explicações dos estudantes pudessem ser questionadas e testadas. Estimulamos a obser- 
vação dos fenômenos celestes e o confronto de tais observações com a teoria.

\section{Conclusões}

A Geologia e a Astronomia proporcionam um olhar integrado, tanto sobre a Terra como para além do sistema solar. A pesquisa sintetizada neste artigo, desenvolvida junto a estudantes de graduação nas carreiras de Ciências da Terra, partiu de uma questão inicial: quais conteúdos, objetivos educacionais e estratégias metodológicas devem compor uma disciplina de Astronomia introdutória para essas carreiras? Da aplicação prática resultou uma proposta ordenada de conteúdos de Astronomia relevantes para cursos de graduação de Geologia, bacharelado e licenciatura em Geografia. A experiência pode ser estendida para outros cursos superiores de formação docente.

A análise das produções dos estudantes indica que a estratégia adotada favoreceu mudanças conceituais significativas. Entretanto, a preferência por atividades práticas em lugar de aulas expositivas não permitiu a abordagem de todos os temas desejados, o que indica a necessidade de número maior de horas semanais para discussão de todos os temas considerados relevantes para os estudantes de Ciências da Terra.

Uma das conclusões do trabalho é que uma disciplina de Astronomia introdutória em cursos superiores pode formar um olhar crítico acerca dos modelos científicos estabelecidos para o planeta e, em paralelo, desenvolver e aprimorar uma perspectiva temporal mais ajustada aos vastos intervalos compreendidos na evolução do universo. Ao mesmo tempo em que a Astronomia revela que os conhecimentos sobre o planeta Terra subsidiam o desenvolvimento das Ciências Planetárias, uma disciplina que aborde tais conteúdos pode mostrar que o entendimento dos corpos celestes e sua dinâmica ajuda a humanidade a interpretar com mais profundidade o planeta onde vive. De certo modo, todo o conjunto de experiências vivenciais contribui para formar nos cidadãos uma concepção mais realista sobre consequências práticas de suas escolhas e decisões, tanto individuais, quanto coletivas.

\section{Agradecimentos}

Os autores agradecem o apoio do Prof. Dr. Oscar Braz Mendonza Negrão, que participou ativamente do desenvolvimento da disciplina de Astronomia no Instituto de Geociências da Unicamp, no ano 2009.

\section{Referências}

Abdalla M.C., Villela Neto, T. 2005. Novas janelas para o Universo. São Paulo: Editora UNESP. 120p.

Baker V.R. 1999. Geosemiosis. Geol. Soc. Am. Bull., 111(5):633-645. (Pres. Address). URL: http:// gsabulletin.gsapubs.org/content/111/5/633.full. pdf + html. Acesso 06.10.2014.

Barstow D., Geary E. (org). 2002. Blueprint for Change: Report from the National Conference on the Revolution in Earth and Space Science Education. Boston: TERC. 100p. URL: http://www. earthscienceedrevolution.org/RevEarthSciEd. pdf. Acesso: 29.07.2013

Basilici G., Silva A.M.B. 2010. Projeto Pedagógico dos cursos de graduação em Geologia e Geografia. URL: http://www.prg.unicamp.br/portal/index. php? option $=$ com_docman\&task $=$ doc_down load\&gid $=213 \&$ Itemid $=115 \&$ lang $=$ pt. Acesso: 02.06.2013. URL: http://www.ige.unicamp.br/ terraedidatica/.

Bisch S.M.1998. Astronomia no Ensino Fundamental: natureza e conteúdo do conhecimento de estudantes e professores, São Paulo. São Paulo: Fac. Educação. USP.(Tese Dout.).

Bretones P.S. 1999. Disciplinas introdutórias de Astronomia nos cursos superiores do Brasil, São Paulo. Campinas: Inst. Geoc. Unicamp. 187p. (Dissert. Mestr.).

Castilla G., Pablo M.A. 2003. De puntos en el cielo a paisajes exóticos: el origen de las ciencias planetarias. Enseñanza de las ciencias de la Tierra, 11(3): 163-169.

Carneiro C.D.R., Gonçalves, P.W., Negrão, O.B.M., Cunha, C.A.L. Ciência do Sistema Terra e o entendimento da "Máquina Planetária" em que vivemos. Geonomos, 9(1):1-8.

Carneiro C.D.R. 2008. O Ano Internacional do Planeta Terra: divulgação do conhecimento geológico e educação. Ciência E Ensino, 2(2).

Carneiro C.D.R., Toledo M.C.M.de, Almeida F.F.M.de. 2004. Dez motivos para a inclusão de temas de Geologia na Educação Básica. Rev. Bras. Geoc. 34(4):553-560.

Cervato C., Frodeman R. 2012. The significance of geologic time: cultural, educational, and economic frameworks. The Geological Society of America, Special Paper, 486:19-27. Trad. Por M.C. Briani e P.W. Gonçalves. 2014. A importância do tempo geológico: desdobramentos culturais, educacionais e econômicos). Terrce Didatica, 10(1):67-79. URL: http://www.ige.Unicamp.br/terraedidatica/.

Karttunen H., Kröger P., Oja H., Poutanen M., Donner K.J. 1996. Fundamental Astronomy. Heidelberg: Springer-Verlag. 521p.

Langhi R. 2011. Educação em astronomia: da revisão bibliográfica sobre concepções alternativas à necessicade de uma ação nacional. Cad. Bras. Ens. 
Fís., 28(2):373-399.

Lefevre F. 2005. Discurso do sujeito coletivo: um novo enfoque em pesquisas qualitativas (desdobramentos). Caxias do Sul, RS: Educs. 256p.

Lópes-Llamas C. 2003. El futuro de las ciencias planetarias em el sistema educativo de secundaria. Enseñanza de las ciencias de la Tierra, 11(3):181-186.

Nield T., Derbyshire E. 2007. Planet Earth in our hands. Texto orig. por Leenaers H., Schalke H. 2004. Leiden, The Netherlands, Earth Sciences for Society Foundation. URL: www.yearofplanetearth.org. Acesso: 25.07.2013.

Oliveira K.S., Saraiva M.F.O. 2000. Astronomia e Astrofísica. Porto Alegre: Ed. Universidade/ UFRGS.

Pitman A.J. 2005. On the role of Geography in Earth System Science. Geoforum, 36:137-148

Posner G.J., Strike K.A., Hewson P.W., Gertzog W.A.
1982. Accomodation of a Scientific Conception: toward a theory of conceptual change. Science Education, 66(2):211-227.

Press F., Siever R., Grotzinger J., Jordan T. H. 2006. Para entender a Terra. Porto Alegre: Bookman. 656p.

Silveira F.L. 2003. Marés, fases principais da Lua e bebês. Cad. Bras. Ens. Fís., 20(1):10-29.

Sobreira P.H.A. 2002. Astronomia no Ensino de Geografia: análise crítica dos livros didáticos de geografia, São Paulo. São Paulo: Fac. Filosofia, Letras e Ciências Humanas. USP. 274p. (Dissert. Mestrado).

Sobreira P.H.A. 2005. Cosmografia Geográfica: A Astronomia no Ensino de Geografia, São Paulo. São Paulo: Fac. Fil., Letr. Ciênc. Hum. USP. 239p. (Tese Dout.).

Teixeira W., Fairchild T.R., Toledo M.C.M., Taioli F. orgs. 2008. Decifrando a Terra. São Paulo: Cia. Edit. Nac. 623p. 